\title{
The Curious Nature of the Hemispheric Symmetry of the Earth's Water and Energy Balances
}

\author{
Graeme L. Stephens ${ }^{1,2}$ • Maria Z. Hakuba ${ }^{3}$ - Matt Hawcroft ${ }^{4}$ - Jim M. Haywood ${ }^{4,5}$. \\ Ali Behrangi ${ }^{1}$ - Jennifer E. Kay ${ }^{6}$. Peter J Webster ${ }^{7}$
}

Published online: 26 July 2016

(C) Springer International Publishing AG 2016

\begin{abstract}
This paper presents new estimates of the hemispheric energy balance based on an assembly of radiative flux and ocean heat data. Further, it provides an overview of recent simulations with fully coupled climate models to investigate the role of its representation in causing tropical precipitation biases. The energy balance portrayed here features a small hemispheric imbalance with slightly more energy being absorbed by the Southern hemisphere. This yields a net transport of heat towards the NH composing of a northward crossequatorial heat transport by the oceans and a southward heat flow in the atmosphere. The turbulent fluxes and hemispheric precipitation balance to about $3 \mathrm{Wm}^{-2}$ with slightly larger total accumulation occurring in the $\mathrm{NH}$. CloudSat data indicate more frequent precipitation in the $\mathrm{SH}$ implying more intense precipitation in the NH. Fully coupled climate model simulations show that reducing hemispheric energy balance
\end{abstract}

This article is part of the Topical Collection on Global Energy Budgets

Maria Z. Hakuba

Maria.Z.Hakuba@jpl.nasa.gov

1 Jet Propulsion Laboratory, California Institute of Technology, Pasadena, CA 91109, USA

2 Department of Meteorology, University of Reading, Reading, UK

3 Department of Atmospheric Sciences, Colorado State University, Ft Collins, CO 80523, USA

4 College of Engineering, Mathematics and Physical Sciences, University of Exeter, Exeter, UK

5 Met Office Hadley Centre, Exeter, UK

6 Cooperative Institute for Research in Environmental Sciences, University of Colorado, Boulder, CO 80309, USA

7 School of Earth and Atmospheric Sciences, Georgia Institute of Technology, Atlanta, GA 30332, USA biases does little to reduce existing biases in tropical precipitation.

Keywords Hemispheric energy balance $\cdot$ Surface heat budget - Ocean heat storage $\cdot$ Cross-equatorial heat transport . Fully coupled climate model $\cdot$ Tropical precipitation bias

\section{Introduction}

The Earth's climate is determined by the flows (fluxes) of energy into and out of the planet and to and from the Earth's surface. The geographical distributions of these fluxes are particularly important as the latitudinal variation of the top of the atmosphere (TOA) fluxes establishes one of the most fundamental aspects of Earth's climate determining how much heat is transported from low latitudes to high latitudes (e.g., [16, 66, 74] among many others). The further disposition of net TOA energy between the atmosphere and surface is also of fundamental relevance to climate (e.g., [22, 23]). The surface energy fluxes are fundamental to understanding the carbon, energy, and water nexus. Surface energy fluxes drive ocean circulations, determine how much water is evaporated from the Earth's surface, and govern the planetary hydrological cycle (e.g., [76]). Changes to the surface energy balance also ultimately control how this hydrological cycle responds to the small energy imbalances that force climate change $[2,3,51,60]$.

Despite the fundamental importance of the energy balance to our understanding of climate and climate change, there still remain a number of challenges in quantifying it globally and in understanding its behavior regionally. Current depictions of the global surface energy balance (e.g., [41, 62-64]) indicate that uncertainties attached to our best depiction of the net surface energy balance are an order of magnitude larger than the small imbalance of approximately $0.6 \pm 0.43 \mathrm{Wm}^{-2}$ that is 
inferred to exist from the ocean heat content $(\mathrm{OHC})$ changes (e.g., [43] among several others). Although the uncertainty in TOA fluxes is also larger than this inferred imbalance, both Wong et al. [77] and later Loeb et al. [46] demonstrated that changes to TOA net fluxes generally track the changes in OHC suggesting TOA flux balances could be tuned to $\mathrm{OHC}$ changes. It is for this reason that Loeb et al. [46] apply the global values of $\mathrm{OHC}$ as a constraint on the global TOA radiation balance. Nonetheless, Trenberth et al. [70] note that there are still important discrepancies between $\mathrm{OHC}$ data and the TOA net flux observations, thus suggesting that even this constraint approach has significant uncertainties with respect to closing the TOA energy balance. No equivalent data record exists for the net energy balance at the surface and no attempt has been made to examine the extent that the global surface energy balance changes also track $\mathrm{OHC}$ changes.

Recently, considerable interest has been directed towards understanding the more regional changes in energy balance and much of this interest has developed around the study of the hemispheric energy balances. Hemispheric energy balances have been invoked to explain the northern annual average location of the intertropical convergence zone (ITCZ) (e.g., $[20,30,31,49])$ and to evaluate the realism of climate models using observations $([17,28,65])$. The properties of this hemispheric balance are updated and reviewed in this study. The various sources of data used in this update are summarized in the next section. Because energy and water are synonymous within the Earth system, the present study also goes beyond the energy balance viewpoint and discusses the hydrological cycle on a hemispheric scale in "The Hemispheric Energy Balance". The impact of a hemispherically symmetric energy balance is explored in "Symmetry in Earth System Models (ESMs)" in the form of model experiments that apply adjustments to make the solar reflection approximately symmetric. A series of recent global Earth-system model studies $[24,25,36]$ have highlighted the acute sensitivity of Earth's climate and hydrological cycle to the degree to which the hemispheric albedo is symmetric and highlights from these studies are reviewed in "Symmetry in Earth System Models (ESMs)". Consistent with observations, these modeling studies underscore the importance of advancing dynamical understanding using modeling frameworks that represent the fully coupled and dynamic global atmosphere and ocean circulations.

\section{Data and Methods}

\section{Ocean Heat Content}

The ocean heat content $(\mathrm{OHC})$ is commonly computed by vertically integrating the ocean temperature profiles multiplied by the density and specific heat of sea water [4, 43].
Three different sources of quality controlled and gridded temperatures are used: The National Oceanic and Atmospheric Administration (NOAA, [42]), the Scripps Institution of Oceanography [55], and the International Pacific Research Center (IPRC). These datasets can be downloaded at www. argo.ucsd.edu/Gridded fields.html and www.nodc.noaa. gov/OC5/3M HEAT CONTENT/. While the Scripps and IPRC datasets combine only Argo float data, the NOAA dataset also includes other in situ measurements, such as expendable bathythermograph (XBT), conductivity, temperature, and depth (CTD) instruments, and mooring data. These datasets contain ocean measurements above $2,000 \mathrm{~m}$ depth over the period 2005-2015. The ocean heat storage (OHS) of the last decade was derived from these data after applying robust regression (using iteratively reweighted least squares) to the global and hemispheric $\mathrm{OHC}$ time series.

\section{Cross Equatorial Ocean Heat Transport}

A cross-equatorial heat transport exists as a consequence of the differential ocean heat content between hemispheres. We make use of various global ocean reanalysis and observationbased surface heat flux $\left(F_{\mathrm{s}}\right)$ datasets, which, integrated meridionally and zonally, depict the long-term averaged meridional heat transport. Our main foci are the ECCOv4 [18] and GECCO2 (Köhl, 38) datasets that are based on the same model (MITgcm), but employ different adjusted forcing fields and bulk formulae. Within the Ocean Reanalysis Intercomparison Project (ORA-IP, [5]), these datasets are shown to be least affected by interior sources and sinks of heat associated with the temperature assimilation and exhibit nearly closed global budgets [71]. For comparison, we include six other datasets, namely the Global Ocean Data Assimilation System Global Ocean Physics Reanalysis C- GLORS [67], the NCEP Global Ocean Data Assimilation System (GODAS, [7]), the CORE.2 Global Air-Sea Flux Dataset [40], the satellite-based JOFURO2 dataset [39], the NOCS Surface Flux Dataset v2.0 based on ICOADS v2.4 ship data, and the WHOI Objectively Analyzed air-sea Fluxes (OAFlux, [79]). Detailed specifics and a comparison of these data products are provided in Balmaseda et al. [5] and Valdivieso et al. [71].

The oceanic meridional heat transport derived from the ocean surface net heat flux from historical simulations of 35 models archived under the IPCC-AR5/CMIP5 [68] (http://cmip-pcmdi.llnl.gov/cmip5/) is contrasted against the observation-based transports. The historical simulations were derived from models forced by observed atmospheric composition changes reflecting both the anthropogenic (greenhouse gases and aerosols) and natural sources (volcanic, solar forcing, aerosols and emissions of short-lived species and their precursors). The simulations cover much of the industrial period from the mid-nineteenth century to the present and are sometimes referred to as "twentieth century all forcings" 
simulations. In our analysis we make use of a 15 -year climatology based on the last 15 years of the simulation period (1991-2005).

\section{Heat Balance Data}

Top-of-atmosphere and surface radiative fluxes are from the latest CERES EBAF v2.8 datasets [34, 46]. The shortwave and longwave TOA fluxes are adjusted within their range of uncertainty to be consistent with the global heating rate inferred from in-situ ocean observations and model simulations $[45,46]$. The global mean TOA reflected solar irradiance during the period $2000-2010$ is $100 \mathrm{Wm}^{-2}$ with a stated uncertainty in absolute calibration of $2 \%(2 \sigma)$ or $4 \mathrm{Wm}^{-2}$ [45]. The surface irradiances in the version 2.8 CERES EBAF surface product [34] are based on the CERES SYN1deg-lite product and radiative transfer calculations with satellite-retrieved surface, cloud, and aerosol properties as input $[15,33,34,56]$. CERES EBAF surface fluxes have been shown to agree unprecedentedly well with in situ land surface and ocean observations [22, 34].

With the assumption that both the annual heat storage and transport are negligible over land and within the cryosphere [9], the hemispheric surface net heat flux $\left(F_{\mathrm{s}}\right)$ is obtained as the residual of the hemispheric OHS and cross-equatorial ocean heat transport $(\mathrm{COHT}): F_{\mathrm{s}}=\mathrm{OHS}-\mathrm{COHT}$. With this novel approach, we constrain the hemispheric $F_{\mathrm{s}}$ by the observed hemispheric OHS. This requires an estimate of the net amount of heat that is moved from one hemisphere to the other. We estimate the COHT indirectly by integrating $F_{\mathrm{s}}$ over the area of the ocean ("Cross Equatorial Ocean Heat transport" section) from pole to equator (e.g., [20]) as opposed to applying the direct method of integrating ocean temperatures and current velocities [52]. This may imply a circular argument in the context of deriving the hemispheric $F_{\mathrm{s}}$, but allows us to exploit a large number of datasets ("Cross Equatorial Ocean Heat transport" section), providing firstorder estimates that compare well to previous estimates (see below). An improved representation of the COHT considering ocean dynamics is proposed for a future study.

The surface turbulent fluxes are inferred as a residual of the surface radiative budget (CERES EBAF) and the surface net heat flux derived from the ocean data. This approach to estimate the hemispheric energy budget and the terms that define it differs from the recent analyses of Loeb et al. [47] and Liu et al. [44]. These latter studies combine the total and atmospheric heat budgets derived from satellite-retrieved TOA irradiances (CERES) and atmospheric reanalysis (ERAInterim) to infer the surface heat budget as their residual.

Here, the atmospheric heat budget is the residual of the total (derived from CERES TOA fluxes) and the surface heat budget. The total and atmospheric heat transports across the equator correspond to the halved difference between the hemispheric energy budgets and are converted to PW considering a hemispheric surface area of $2.55 \times 10^{14} \mathrm{~m}^{2}$.

\section{Cloud and Precipitation Data}

Analysis of cloud and precipitation data derived from the CloudSat spaceborne cloud-profiling radar (CPR, [59]) also provide context for the discussion of the hemispheric properties of precipitation. The data used are the 2B-GEOPROFlidar profile data that provide our most definitive measure of cloud top heights and cloud area fractions [48] and the occurrence of precipitation based on the most recent version of $2 \mathrm{C}$ COLUMN-PRECIP product that determines the incidence of precipitation from estimates of the path-integrated attenuation (PIA) of the CPR. This version has been extended to include precipitation over land (e.g., [58]). Other precipitation data include the version 2.2 Global Precipitation Climatology Project (GPCP) [1, 26], ERA-interim [14, 57], The Modern Era Retrospective-Analysis for Research and Applications (MERRA) [11, 53], and the National Centers for Environmental Prediction-Department of Energy Reanalysis 2 (NCEP-DOE R2) product [29]. GPCP is a merged product using data from gauges over land, and from spaceborne sensors over both land and ocean including Special Sensor Microwave Imager (SSMI), Special Sensor Microwave Imager/Sounder (SSMIS), and geostationary and polar orbiting infrared imagers and sounders. The latest version (V2.2) of the monthly $2.5^{\circ} \times 2.5^{\circ}$ resolution is used in this study. ERA-interim relies on a 4D-VAR (rather than 3D-Var as in ERA-40) system which uses observations within 12-h windows to initialize forecast simulations. This study uses daily precipitation maps at $1.5^{\circ} \times 1.5^{\circ}$ spatial resolution. MERRA uses the Goddard Earth Observing System Data Assimilation System version 5 (GEOS-5; [53]) to assimilate observations (e.g., radiance data) for the retrospective analyses. In the present study, precipitation is obtained from the latest version of the MERRA product (V 5.2) with resolution of $2 / 3^{\circ}$ longitude by $1 / 2^{\circ}$ latitude. NCEP-DOE R 2 uses a global data assimilation system and numerical weather prediction model to produce atmospheric analyses using historical data and also to produce analyses of the current atmospheric state. The spatial and temporal resolutions of the product are $\sim 1.875^{\circ} \times 1.875^{\circ}$ and four times daily, respectively.

\section{Ocean Heat Content and Transports}

Time series of the global and hemispheric $\mathrm{OHC}$ for the period between 2005 to 2015 (seasonal anomalies) based on three different datasets provided by the Scripps, NOAA, and IPRC are presented in Fig. 1. The global OHC (gray and black lines) linearly increases with time and corresponds to an OHS of $0.5 \pm 0.1 \mathrm{Wm}^{-2}$ when averaged over the entire Earth's 
Fig. 1 Seasonal anomalies (2005-2015) of ocean heat content $\left(\mathrm{OHC}, \mathrm{Jx} 10^{22}\right)$ derived from three gridded in situ temperature datasets (gray lines), together with their global (black), $\mathrm{NH}$ (purple), and $\mathrm{SH}$ average (orange). The corresponding ocean heat storage (OHS, in watt per square meter) with respect to the ocean surface and total surface is derived using robust regression

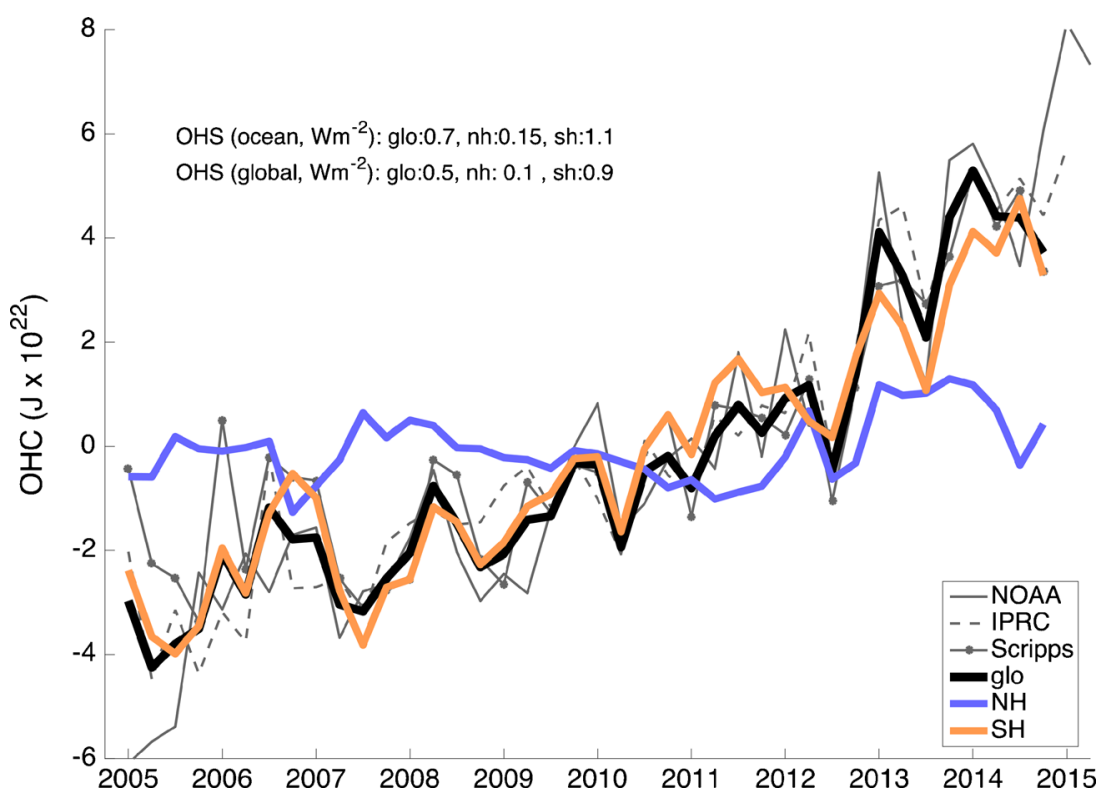

surface. The uncertainty range corresponds to the OHS range between the three data products and is consistent with trend uncertainty estimates derived from Argo data by von Schuckmann and Le Traon [75]. By design, this global mean OHS is reproduced in the TOA radiation flux imbalance (Fig. 4). The hemispheric OHC is provided by the colored curves in Fig. 1 and the OHS reveals that the global heat uptake of the oceans predominantly occurs in the Southern hemisphere oceans (orange line) at a rate of $0.9 \pm 0.1 \mathrm{Wm}^{-2}$ in agreement with the previous studies of Roemmich et al. [54] and Nieves et al. [50]. The OHC data suggest little heat $\left(0.1 \pm 0.1 \mathrm{Wm}^{-2}\right)$ is being accumulated in the Northern hemisphere oceans (purple line).

Figure 2 presents the meridional heat transport within the oceans (OHT) derived by meridionally and zonally integrating the ocean $F_{\mathrm{s}}$ obtained from the eight data sources noted above. Half of the datasets are substantially out of balance (Fig. 2, top) except for the ECCOv4 (black), GECCO2 (blue), GODAS (orange), and CORE.2 (green). Hence, we subtract the global mean imbalance in $F_{\mathrm{s}}$ from each dataset (values given in the legend of Fig. 2, bottom) and present the corrected OHT in Fig. 2 (bottom). The ECCO products and balanced NOCS dataset [8] agree best with the hydrographic estimates of Ganachaud and Wunsch [21] on both hemispheres (yellow squares including uncertainty range). These were obtained during the World Ocean Circulation Experiment and typically serve as a reference to ocean model solutions (e.g., [71]). The well-balanced GODAS and CORE. 2 datasets show reasonable agreement in the Northern hemisphere as well, but underestimate the poleward transport in the Southern hemisphere. In Fig. 2 (bottom), two clusters of COHT are evident. While the J-OFURO2, CORE.2, OAFlux, and GODAS products' COHT is on average (median) $1.02 \mathrm{PW}$ (black circle, Fig. 2, bottom), the ECCOv4, GECCO2, NOCS, and C-
GLORS estimates average to $0.45 \mathrm{PW}$ (red circle). As the latter agree better with the hydrographic estimates, we adopt $0.45 \mathrm{PW}$ as our best estimate for COHT, which is in remarkable agreement with estimates by Loeb et al. [47] and Marshall et al. [49]. As a first-order estimate of uncertainty that covers the range of COHT values found here, we take the most conservative estimate by Ganachaud and Wunsch [21], suggesting an uncertainty of up to $\pm 0.6 \mathrm{PW}$ at $19^{\circ}$ South due to Ekman transport and inverse model errors.

Figure 3 presents the multi-model median OHT derived from the historical simulations of 35 CMIP5 models (purple) contrasted against the transports inferred from ECCOv4 (black) and the hydrographic estimates (yellow squares) by Ganachaud and Wunsch [21]. On average, the ocean $F_{\mathrm{s}}$ in these simulations is $+0.8 \mathrm{Wm}^{-2}$ out of balance and has been corrected for accordingly. The shading represents the model spread in terms of the median absolute deviation at each latitude. The box plot to the right summarizes the CMIP results for the cross-equatorial flow with the ECCOv4 (black dot), GECCO2 (blue), GODAS (orange), CORE.2 (green), J-OFURO2 (light gray), NOCS (dark gray), OAFlux (asterisk), C-GLORS (black square) results superimposed. The model median transport is $\sim 0.6$ PW (left: red circle, right: red line) but the inter-model spread is substantial as indicated by the interquartile range (box) and total range (whiskers). The net transport of 0.6 PW is well above our best estimate, but lies within the error estimate at $0.45 \pm 0.6 \mathrm{PW}$.

\section{The Hemispheric Energy Balance}

Figure 4 brings the various data sources together providing a summary of the hemispheric energy budget of Earth. All 
Fig. 2 (Top) Meridional ocean heat transport (OHT, PW) from zonally integrated surface net heat flux taken from eight different ocean reanalysis and observational datasets. (Bottom) Same as top but with global mean imbalance removed (see magnitude in legend). The highlighted cross-equatorial $\mathrm{OHT}$ (red circle) represents the median of ECCOv4, GECCO2, NOCS and C-GLORS at $0.45 \mathrm{PW}$ and median of the other datasets (black circle) at $1.02 \mathrm{PW}$. The yellow squares represent hydrographic estimates and their uncertainties by Ganachaud and Wunsch [21]
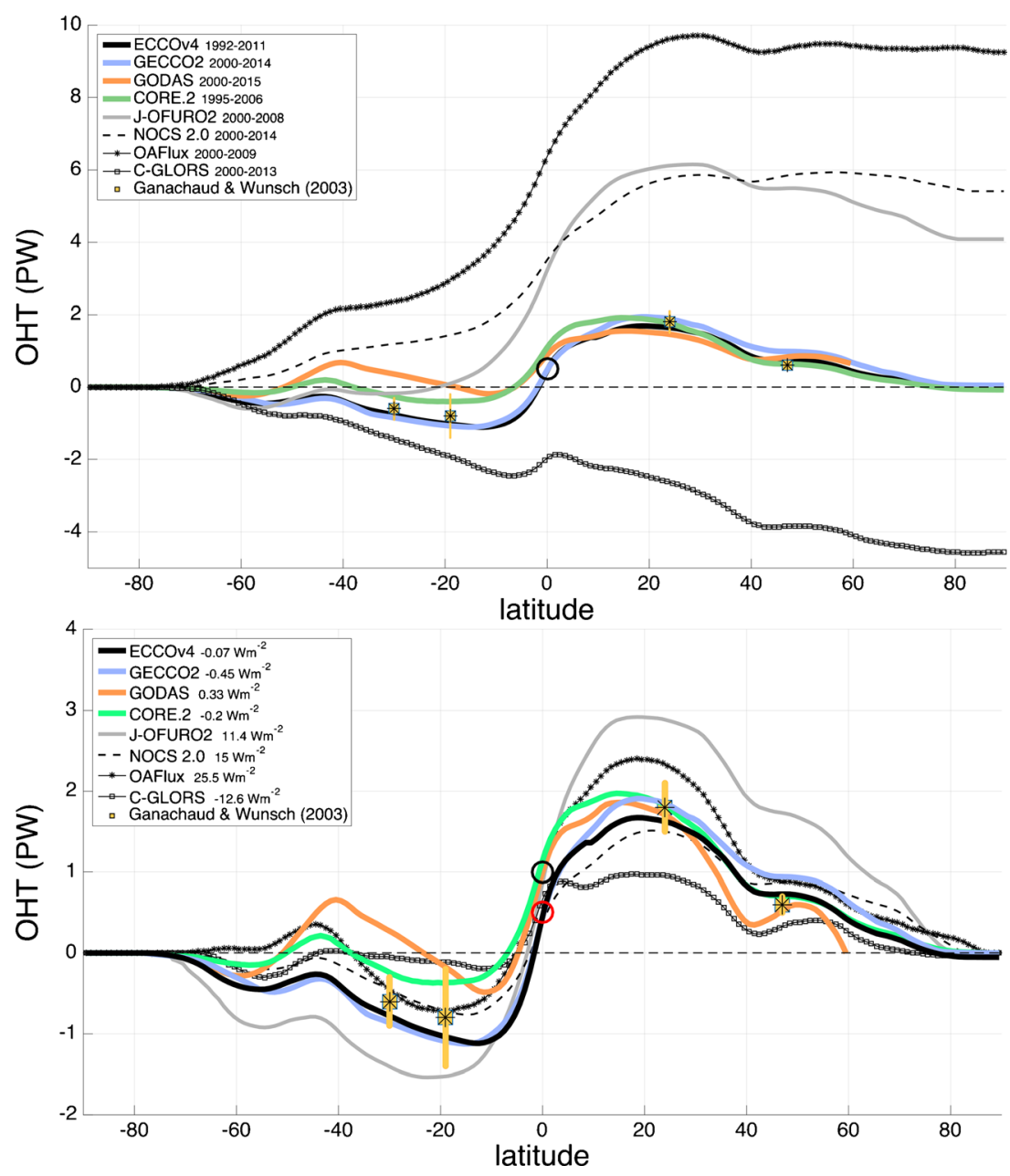

quantities are multi-year averages and some of the fluxes have multiple values. Except for the OHT analysis ("Ocean Heat Content And Transports" section), no attempt has been made to adjust fluxes to provide overall balance in each hemisphere. Rather we have chosen to underscore the range in the values as it conveys both a sense of overall uncertainty and an indication of the degree to which the different data sources are imbalanced. The TOA and surface radiative fluxes are from CERES EBAF for the period 2004-2014, the ocean heat storage estimates are the mean of the sources noted in reference to Fig. 1, the cross-equatorial heat transport within the oceans is the average COHT of ECCOv4, GECCO2, NOCS, and CGLORS (Fig. 2), the atmospheric heat budget is the residual of the total (derived from CERES TOA zonally and annually averaged fluxes) and the surface heat budget. As for the total heat transport, the cross-equatorial heat transport in the atmosphere is deduced from the hemispheric contrast in the atmospheric energy budget, assuming a hemispheric surface area of $2.55 \times 10^{14} \mathrm{~m}^{2}$ (see Eq. 3 in [47]).

Surface turbulent fluxes are deduced as a residual of the surface heat budget (OHS-COHT), and the CERES EBAF surface radiative fluxes. The values of the hemispheric fluxes and transports taken from Loeb et al. [47] are also provided for comparison and given in parentheses. Although a different period is considered (2004-2014 vs. 2001-2012 in [47]), the net heat fluxes at TOA are essentially the same. However, in contrast to Loeb et al. [47] who assume hemispheric symmetry in OHS, we implicitly take into account that heat entering the oceans $\left(F_{\mathrm{s}}\right)$ is either stored (OHS) or exchanged between the hemispheres (COHT). The COHT of $0.45 \mathrm{PW}$ corresponds to $1.8 \mathrm{Wm}^{-2}$ being moved from the $\mathrm{SH}$ to the $\mathrm{NH}$. With the OHS of $0.9 \mathrm{Wm}^{-2}(\mathrm{SH})$ and $0.1 \mathrm{Wm}^{-2}(\mathrm{NH})$, the respective values of $F_{\mathrm{s}}$ are $2.7 \mathrm{Wm}^{-2}(\mathrm{SH})$ and $-1.7 \mathrm{Wm}^{-2}(\mathrm{NH})$. The uncertainties to be attached to these transports are large (Fig. 4) and it is not possible to provide a precise closure to the heat balance without some adjustment to individual fluxes.

The total heat transport derived from the hemispheric contrast in CERES EBAF TOA net fluxes is $0.23 \mathrm{PW}$ in contrast to the value of $0.12 \mathrm{PW}$ obtained as to the sum of the oceanic and atmospheric heat transport derived from the hemispheric contrast in the atmospheric heat budget. Likewise, the atmospheric heat transport is at $0.22 \mathrm{PW}$, instead of $0.33 \mathrm{PW}$, if we assume the value of $0.23 \mathrm{PW}$ from CERES at TOA and the COHT of $0.45 \mathrm{PW}$. These differences in the cross equatorial 


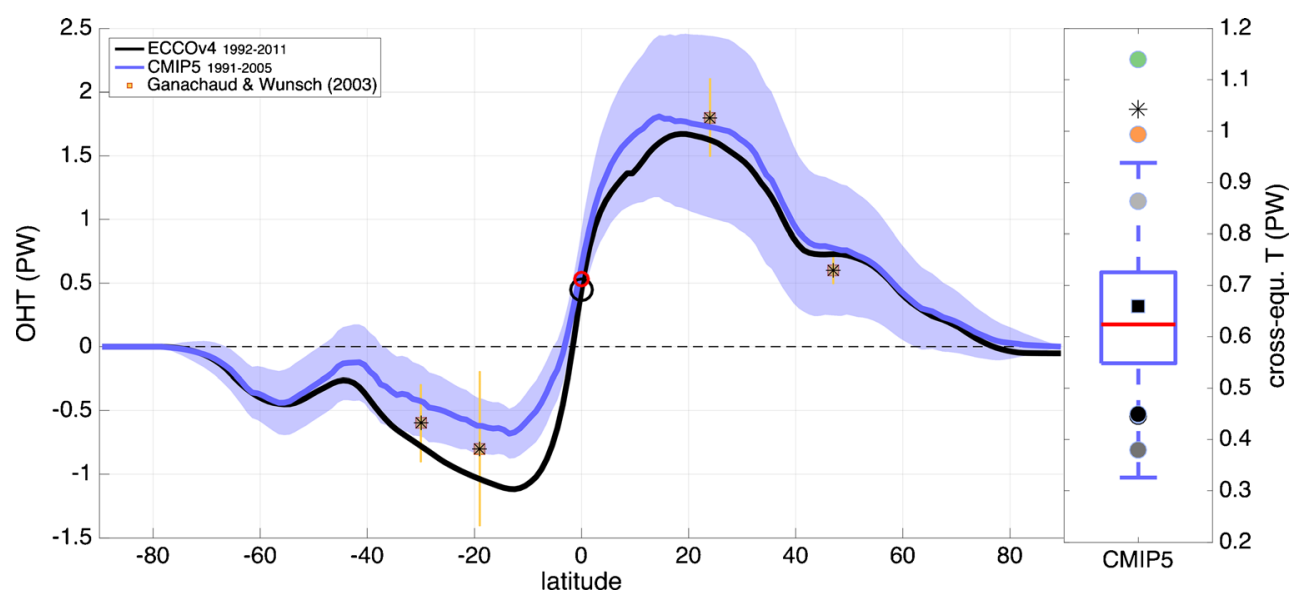

Fig. 3 Meridional oceanic heat transport (OHT, PW) based on the multimodel median of 35 historical CMIP5 simulations (purple) as compared to ECCOv4 (black) and hydrographic estimates (yellow squares) by Ganachaud and Wunsch [21]. The purple shading represents the median absolute deviation at each latitude. The box plot to the right shows the model spread around the multi-model median cross-equatorial OHT (red circle left, red line right) in terms of interquartile range (box) and total range (whiskers). Exempt are the two outliers that lie far outside this range and indicate strong southward transport at the equator. Additionally, we show the estimates based on ECCOv4 (black dot), GECCO2 (blue dot), GODAS (orange dot), CORE.2 (green dot), J-OFURO2 (light gray dot), NOCS (dark gray dot), OAFlux (asterisk), C-GLORS (black square) heat transports are indicative of the uncertainties in estimating the overall closure and within the uncertainty estimate at 0.6 PW (from [21]). While the estimates presented in Fig. 4 leave room for discussion and improvement, they do draw a similar picture to those of Loeb et al. [47].

A notable feature of the energy balance portrayed in Fig. 4 is the near hemispheric symmetry in the TOA energy balance in contrast to the surface radiative fluxes that are slightly more asymmetrical. At the TOA, the SH is slightly out of balance as a result of a small amount of heat being absorbed by the Southern oceans (Fig. 1) whereas the NH appears to be almost in balance. This small hemispheric difference results from a small asymmetry in the OLR (e.g., [64]) as both the incoming solar and reflected solar are almost identical in both hemispheres (e.g., [72, 65]). The slight energy imbalance between the hemispheres implies a net transport of heat across the equator from the $\mathrm{SH}$ to the $\mathrm{NH}$, which composes of a northward heat transport by the oceans and a southward heat transport by the atmosphere. That the NH atmosphere is warmer in the annual mean than the SH (e.g., [32]) is reflected in the difference in surface longwave flux with the $\mathrm{NH}$ emitting almost $7 \mathrm{Wm}^{-2}$ more radiation into the atmosphere from the

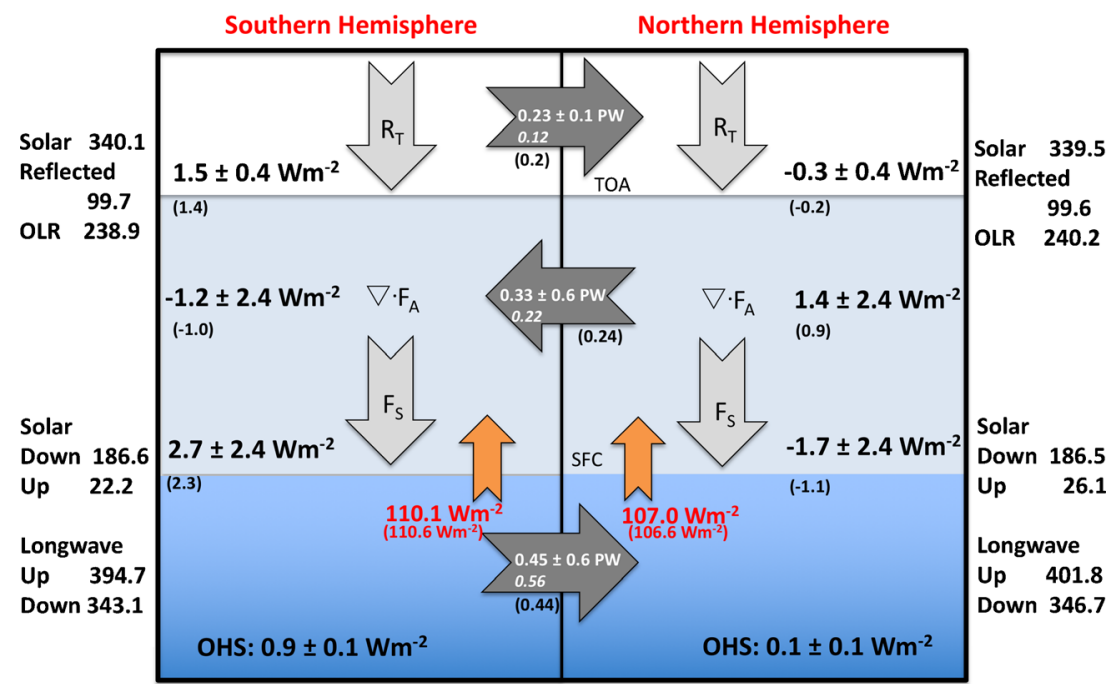

Fig. 4 Hemispheric heat budgets and implied cross-equatorial heat transports at TOA, the surface, and in the atmosphere. The net heat flux at TOA is derived from CERES EBAF (2004-2014) and the attached uncertainties due to radiance-to-flux conversion, time interpolation and interannual variability (square root of summed squares) are adapted from Loeb et al. [47]. The surface heat budget and associated uncertainty is derived from ocean heat storage (OHS, in-situ, 2005-2015) and ocean heat transport $(\mathrm{OHT})$. Uncertainties in OHS $\left(0.1 \mathrm{Wm}^{-2}\right.$, derived from Argo data by von Schuckmann and Le Traon [75]) and OHT (0.6 PW, Ganachaud and Wunsch [21]) add up to $2.4 \mathrm{Wm}^{-2}$ in $F_{\mathrm{s}}$ and the atmospheric heat budget. The turbulent fluxes are the residual of the net heat flux and net radiative flux (CERES) at the surface (orange arrows) 
warmer NH surface. The hemispheric energy contrast in turn forces an atmospheric transport of heat of $0.33 \mathrm{PW}$ from the $\mathrm{NH}$ to the SH (or $0.24 \mathrm{PW}$ according to [47]). In order to facilitate such a heat transport away from the warmer $\mathrm{NH}$ atmosphere to the $\mathrm{SH}$, it has been shown that a displacement of the Hadley circulation is required $[19,78]$. This displacement appears to be driven by the northward ocean heat and moisture transports, shifting the precipitation maxima to the NH ([49]; Frierson et al. [20]). The resulting precipitation asymmetry between hemispheres is quantified in the following section.

\section{The Hemispheric Character of the Hydrological Cycle}

That the global hydrological cycle is fundamentally controlled by Earth's energy balance has been understood for many years. Given the global heat imbalance is small and largely resides in the SH (Fig. 1), then the net transport of heat across the equator is also small. Thus the energy control of the hydrological cycle is also expected to apply on the hemispheric scale. Figure 5 provides an analysis of four different sources of global precipitation data separated by hemisphere (Fig. 5, top)
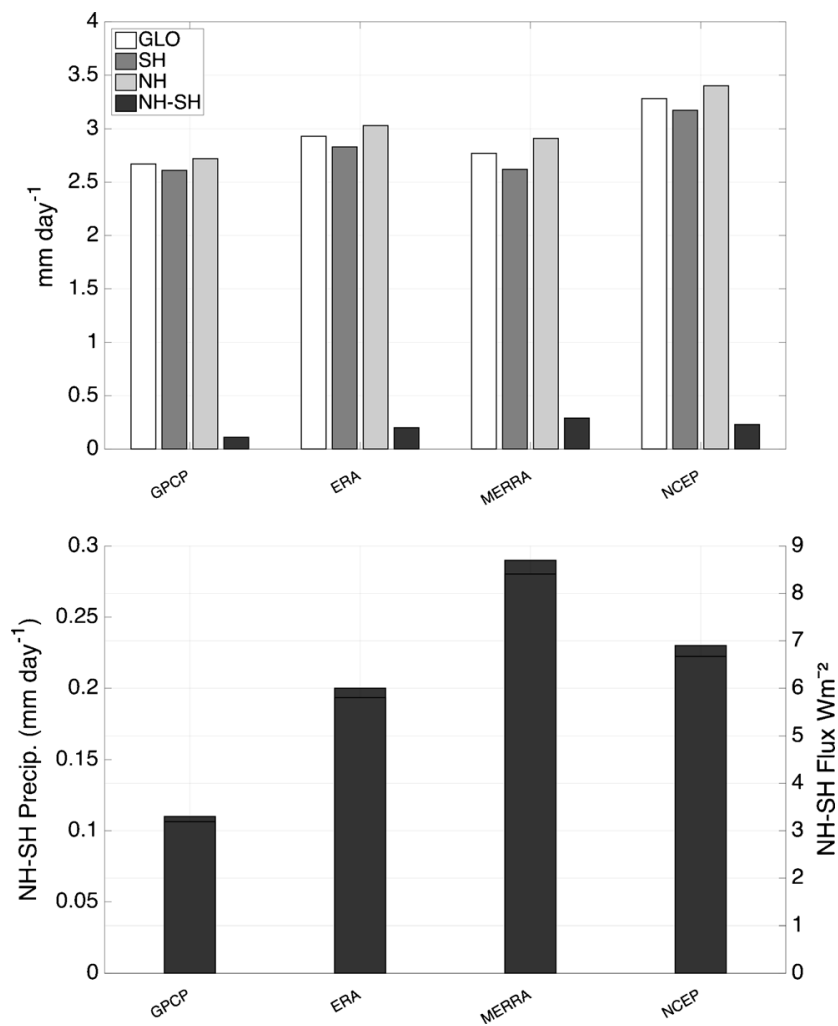

Fig. 5 (Top) Global and hemispheric precipitation from four different sources of data. (Bottom) The NH-SH precipitation accumulation difference in millimeter per day and watt per square meter and also by hemispheric difference (Fig. 5, bottom). Data from three reanalysis data sources as well as the GPCP are compared. The hemispheric differences in annual mean precipitation is $0.11 \mathrm{~mm} /$ day for GPCP which is approximately $4 \%$ of the GPCP global mean. The NH precipitation is slightly greater than in the SH which may have been anticipated given that the climatological mean position of the ITCZ lies in the NH although this difference can be considered to lie within the uncertainties of the observations. The $\mathrm{NH}-\mathrm{SH}$ precipitation differences range between 0.20 and $0.29 \mathrm{~mm} /$ day for the three reanalysis products which is approximately $6.8-10.5 \%$ of the respective global means of these products. This translates to an approximate difference of $3 \mathrm{Wm}^{-2}$ between the hemispheres for the GPCP data and 5.8-8.4 $\mathrm{Wm}^{-2}$ for the reanalyses data. Thus the model-based data indicate a substantially more asymmetric precipitation than is apparent in the observational-based GPCP product. The estimates presented here are conditioned on uncertainties inherent to the data products, especially over the Southern oceans $[6,12]$.

Global statistics on the incidence of precipitation derived from the CloudSat 2C-PRECIP-COLUMN are provided in Figs. 6 and 7. Figure 6 is the global distribution of precipitation incidence accumulated from 4 years of CloudSat data. The incidences shown are for all precipitation types, and the three main modes of precipitation (rain, mixed, and snow) identified in that product. Since precipitation incidence varies according to the scale on which the data are accumulated [61], the incidences shown correspond to an accumulation of observations on a $2 \times 2^{\circ}$ latitude-longitude box. The observations indicate that precipitation tends to be more prevalent at higher latitudes in the form of both mixed precipitation and snow while the incidence of rain is more dominant at lower latitudes. On the hemispheric scale, the $2 \times 2^{\circ}$ incidences shown in Fig. 7 reveal a distinct difference between hemispheres with precipitation in the $\mathrm{SH}$ appearing approximately $17 \%$ more often than the NH. These differences arise from a combination of differences in both rain and mixed phase precipitation. The accumulation (Fig. 5) and incidences of precipitation (Fig. 7) jointly imply that although the NH precipitates less frequently, precipitation is more intense when it occurs. Further research is needed to develop an understanding of the factors that shape these differences and link this behavior to the hemispheric energy budgets portrayed here.

\section{Symmetry in Earth System Models (ESMs)}

Given the observed hemispheric energy imbalance, crossequatorial energy transport, and precipitation asymmetry, several studies have sought to investigate the relationship between these features in climate models. Biases in albedo and 


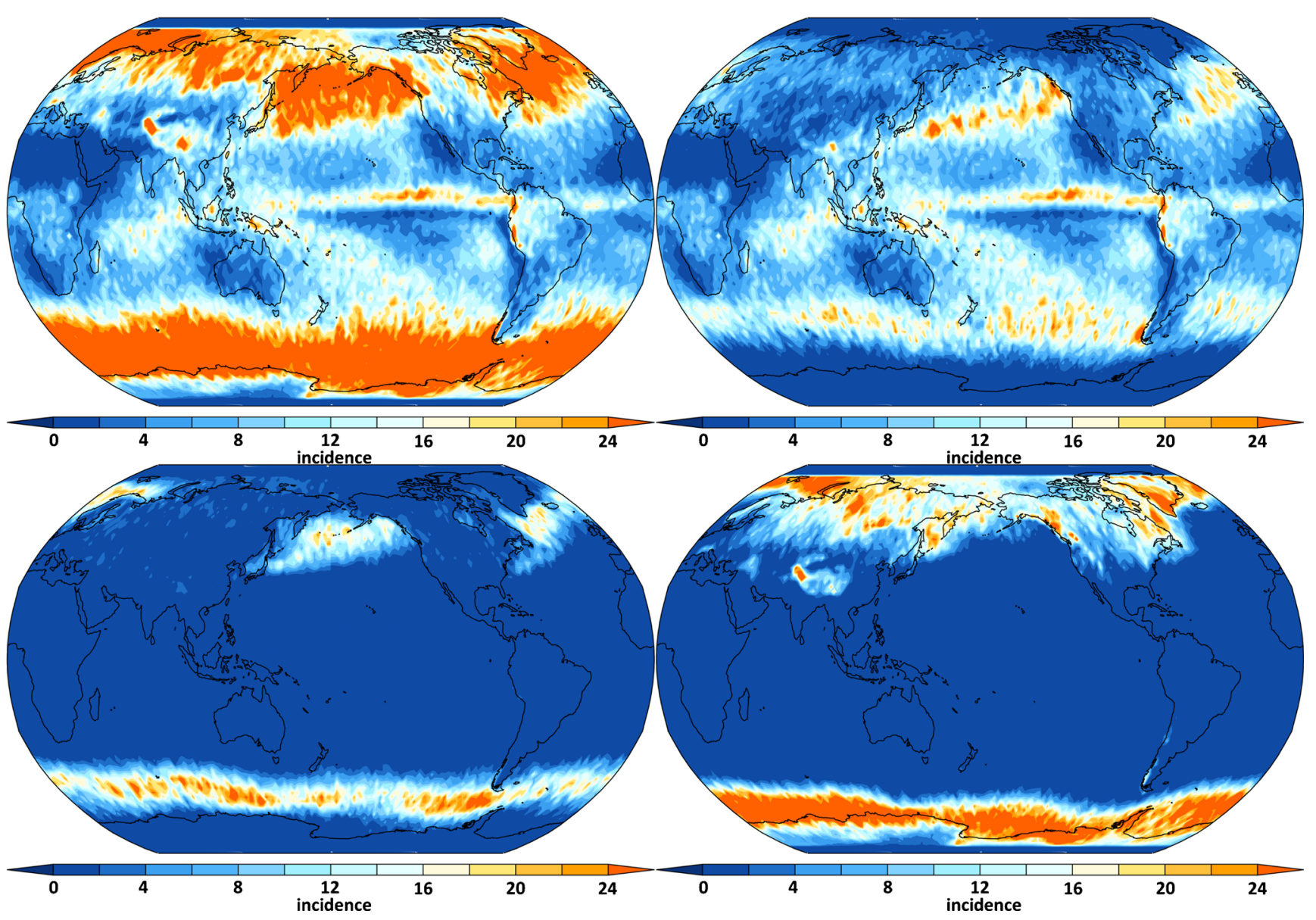

Fig. 6 The incidence of precipitation derived from CloudSat 2C-COLUMN-PRECIP accumulated onto a $2 \times 2$ degree bins. The upper left is the frequency of all types of precipitation, upper right is the rain only, bottom left is mixed phase, and bottom right is snow

TOA energy budgets, with related biases in cross-equatorial energy transport, have been associated with the double ITCZ bias observed in many current climate models (e.g., [28]). Stephens et al. [2015] note that the observed albedo symmetry is not reproduced in the suite of global Earth system models (ESMs) that contributed to the historical CMIP5 simulations. Indeed, a long-standing, large, and ubiquitous radiation bias in climate models is excessive absorption of shortwave radiation

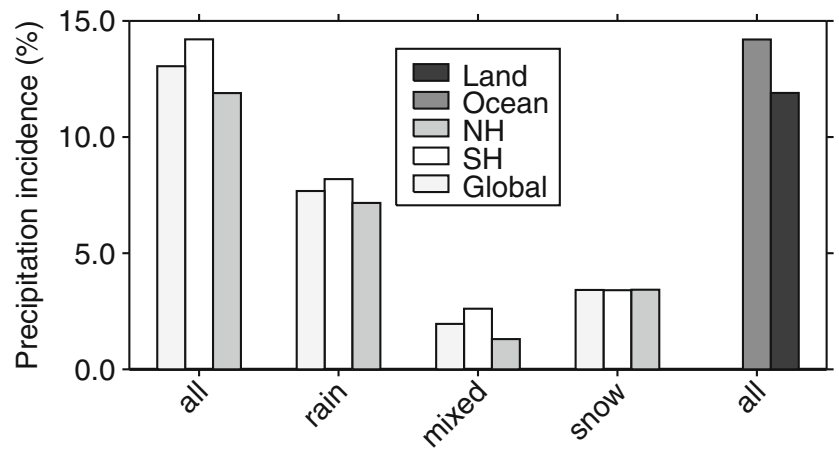

Fig. 7 The globally and hemispherically averaged $2 \times 2$ degree precipitation incidence and incidences over land and ocean (i.e., albedo too low) over the Southern Ocean [28, 69]. Although the potential impact of this lack of hemispheric albedo symmetry has been explored in idealized aqua planet (e.g., [73]) and slab ocean models (e.g., [13, 19]), recent experiments with Earth system models reveal a very different response when the models possess a fully coupled, dynamical ocean $[24,36]$. Indeed, symmetry experiments performed recently using ESMs have yielded surprising results and the results from two classes of recent experiments that used different approaches to force symmetry are reviewed here.

The first class of experiments is reported in Haywood et al. [25]. In these experiments, the albedo of one hemisphere is approximately uniformly adjusted by three different means. These three adjustment methods include introduction of stratospheric aerosol (STRAT experiment), change in the ocean albedo (OCEAN), and change in cloud microphysics (CLOUD) as a way of tuning the symmetry. The adjustments were applied to increase the albedo of the Southern hemisphere, creating a discontinuity in TOA net flux at the equator. Figure 8 contrasts the results of these experiments and the mean of the STRAT, OCEAN, and CLOUD (SOC-mean) against the same historical simulation (HIST) archived in 
CMIP5. Figure 8a summarizes the northward cross-equatorial energy transports (PW) of the HIST and SOC-mean simulations over the 1979-1998 period. The observed total energy transport (Fig. 8a), is also shown. Tabulated values give the cross-equatorial energy transport (PW) from the STRAT, OCEAN, and CLOUD experiments. The main response in these model experiments occurs within the atmosphere and is highlighted in Fig. 8b in the form of a quantitative assessment of the change in the bias with respect to GPCP precipitation for SOC-mean results for the JJA season over six different monsoon land regions. The percentage change in the precipitation bias for each region is remarkable in that the bias is almost universally reduced. Examination of the hemispheric

a

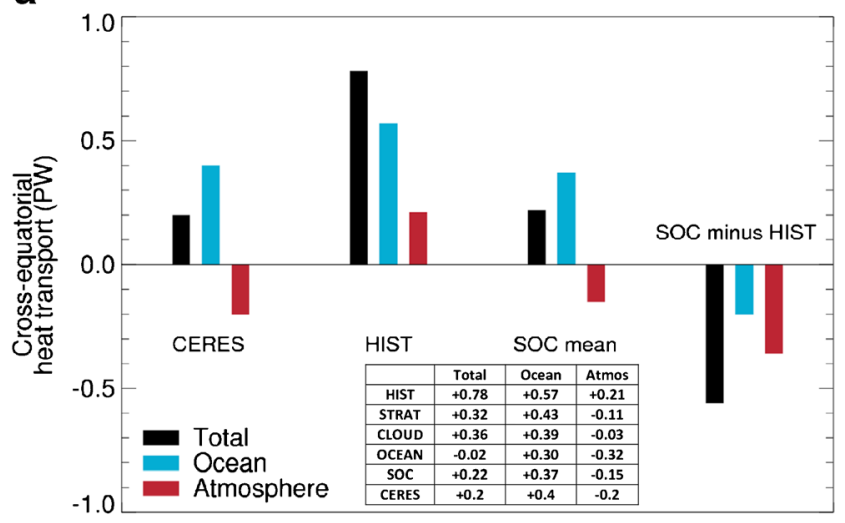

b

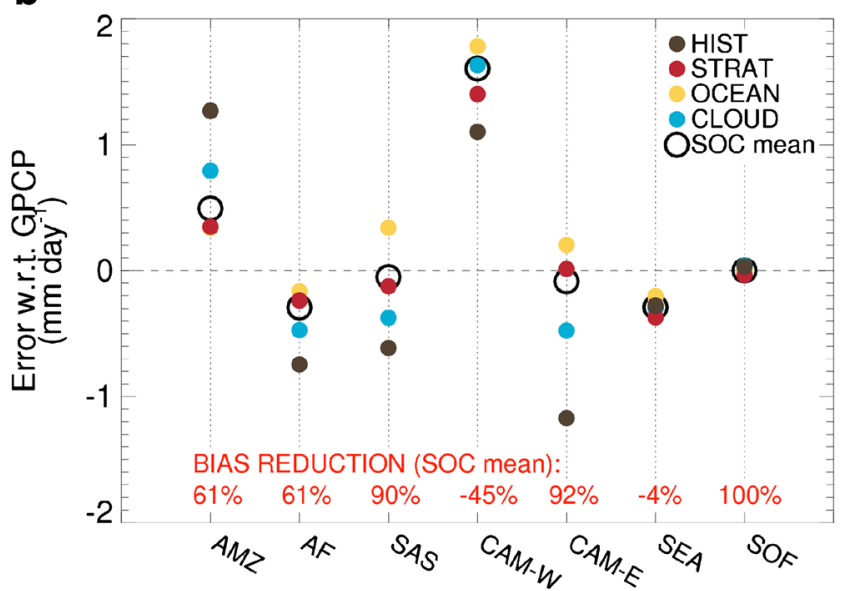

Fig. 8 a A summary of the northward cross-equatorial energy transport (PW) from the HIST and the mean (SOC mean) of the STRAT, OCEAN, and CLOUD simulations over the 1979-1998 period, adapted from the Haywood et al. [25] symmetry experiments. The observed total energy transport derived from CERES, and reproduced on Fig. 4, is also shown. Tabulated values also give the cross-equatorial energy transport (PW) from each of the symmetry experiments. b Quantitative assessment of the change in the bias with respect to GPCP for the JJA season over land in the following regions: $A M Z$, Amazonia; $A F$, Sahelian Africa; $S A S$, South Asia; $C A M-W$, Central America West; $C A M-E$, Central America East; SEA, South East Asia; SOF, Southern Africa from the Haywood et al. [25] experiments. The percentage change in the precipitation biases for SOC mean compared to HIST are quantified for each region (adapted from [25])

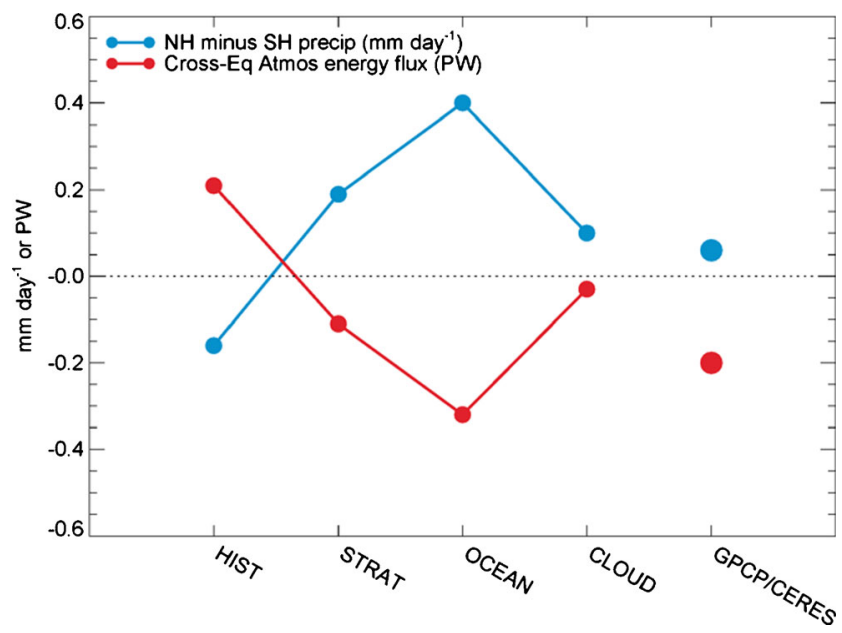

Fig. 9 The NH-SH differences in precipitation (blue) and cross equatorial atmospheric heat transport (red) for the three experiments reported in Haywood et al. [25] as well as the historical model simulation contrasted against the observations (GPCP, Fig. 5 and CERES, Fig, 4)

differences in precipitation provides further insight on the model response to this hemispheric forcing. In the HIST experiments, over the 1991-2005 period considered, the NH$\mathrm{SH}$ precipitation is $-0.16 \mathrm{~mm} /$ day, i.e., the $\mathrm{SH}$ precipitation is larger than the $\mathrm{NH}$ precipitation in contrast to that observed (Fig. 5). The NH-SH precipitation difference for the STRAT simulation changes sign and is $+0.19 \mathrm{~mm} /$ day which is more comparable to the results of Fig. 5. Figure 9 presents these hemispheric precipitation differences together with the cross
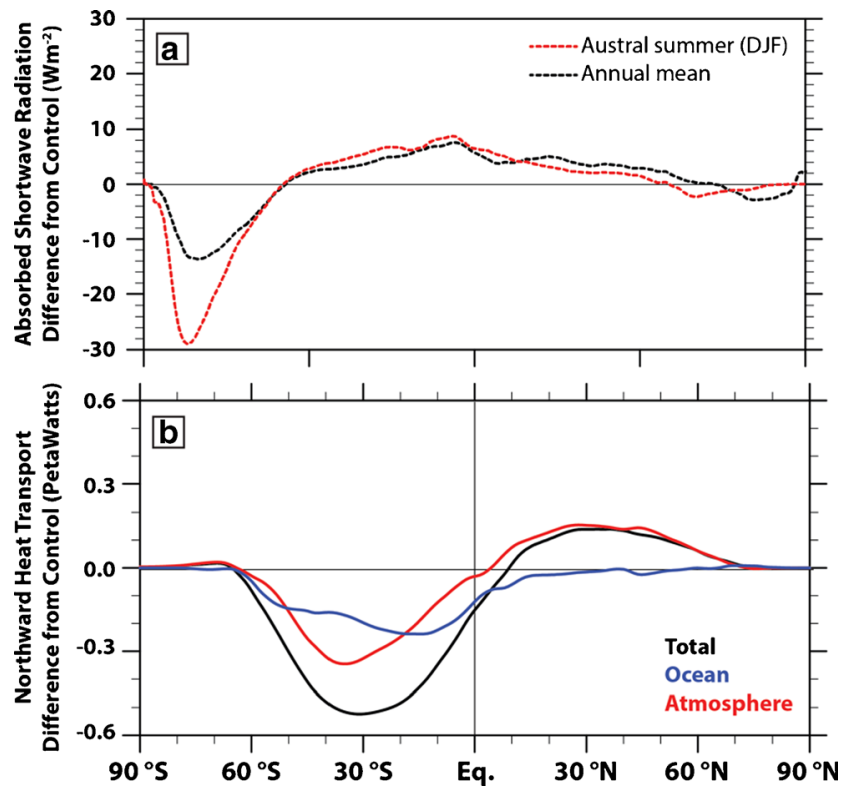

Fig. 10 Climate modeling experiments using CESM showing the impact of increasing supercooled liquid in shallow convective clouds to better match satellite observations from CALIPSO and CERES: a Absorbed shortwave radiation difference from control, $\mathbf{b}$ northward heat transport difference from control. Figure adapted from [36, 37] 
equatorial heat transport for the different experiments reported in Haywood et al. [25]. The precipitation asymmetry is approximately linearly related to the cross-equatorial atmospheric energy transport in the model.

The second class of experiments, reported both by Kay et al. [36] and Hawcroft et al. [24], impose a latitudinally distributed adjustment towards hemispheric symmetry. These two studies were conceived independently. The former study was motivated by a recognition that model mixed-phase cloud physics needed improvement [37] in order to reduce long-standing shortwave radiation biases over the Southern Ocean (i.e., those discussed in [69] and [65]). The latter study, by contrast, was motivated to reduce the longstanding tropical precipitation biases (i.e., via the hypothesis presented in [28]). The adjustments to the absorbed solar radiation in the Kay et al. experiments applied to the Community Earth System Model (CESM) [27, 35] and the resultant change to the meridional heat transport is provided in Fig. 10. Brightening the Southern Hemisphere to produce more realistic symmetrical albedo (Fig. 10a) reduces total northward cross-equatorial heat transport through a reduction in the northward cross-equatorial ocean heat transport but leads to very little change in the cross-equatorial atmospheric heat transport (Fig. 10b). Figure 11a shows the cross equatorial heat transport response in four experiments described by Hawcroft et al. [24] where idealized albedo adjustments are applied to the HadGEM2-ES, the model used by Haywood et al. [25], and are targeted at the source regions of inter-hemispheric albedo bias, particularly the Southern Ocean [10]. Hawcroft et al.'s experiments largely result in a closer hemispheric equilibration of albedo than in the control model, with associated adjustments to cross-equatorial energy transport. The largest adjustment to the cross equatorial transport occurs within the oceans (Fig. 11a)
Fig. 11 a Similar to Fig. 8a but for four different experiments (SWex1-4) performed using the HadGEM2-ES model to alter the hemispheric imbalance in reflected sunlight at the top of atmosphere, showing absolute values and change from the model climatology (CLIM) with the observations denoted as OBS. b The zonally averaged anomalies (SWex-CLIM) in meridional energy transport (in PW) in three ocean basins and for the total global ocean for each SWex experiment (adapted from [24])

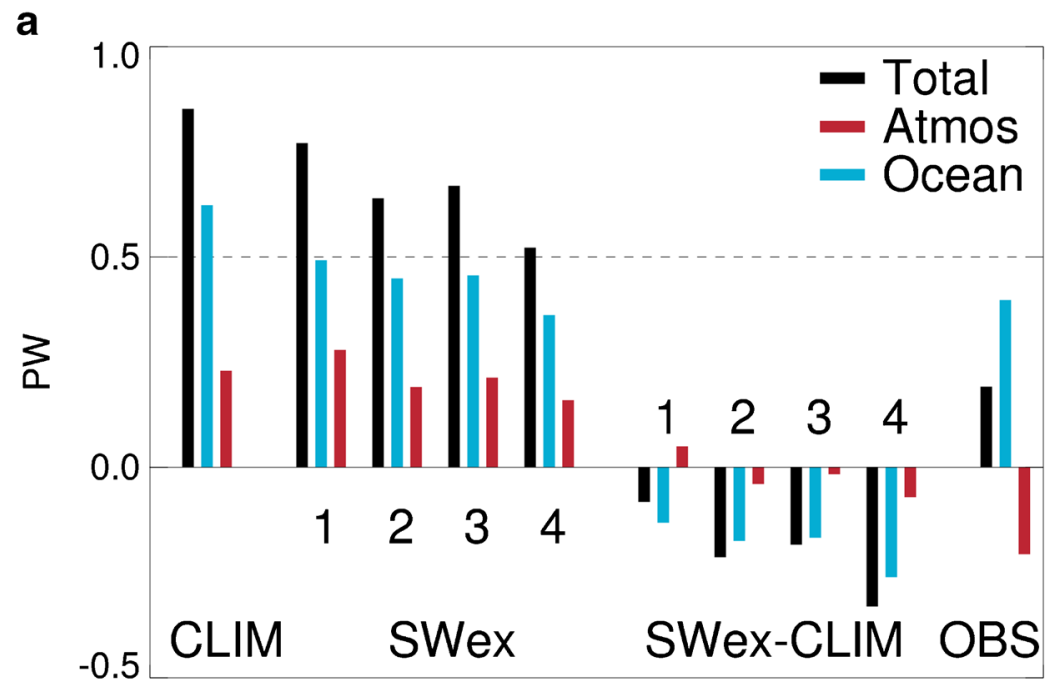

b
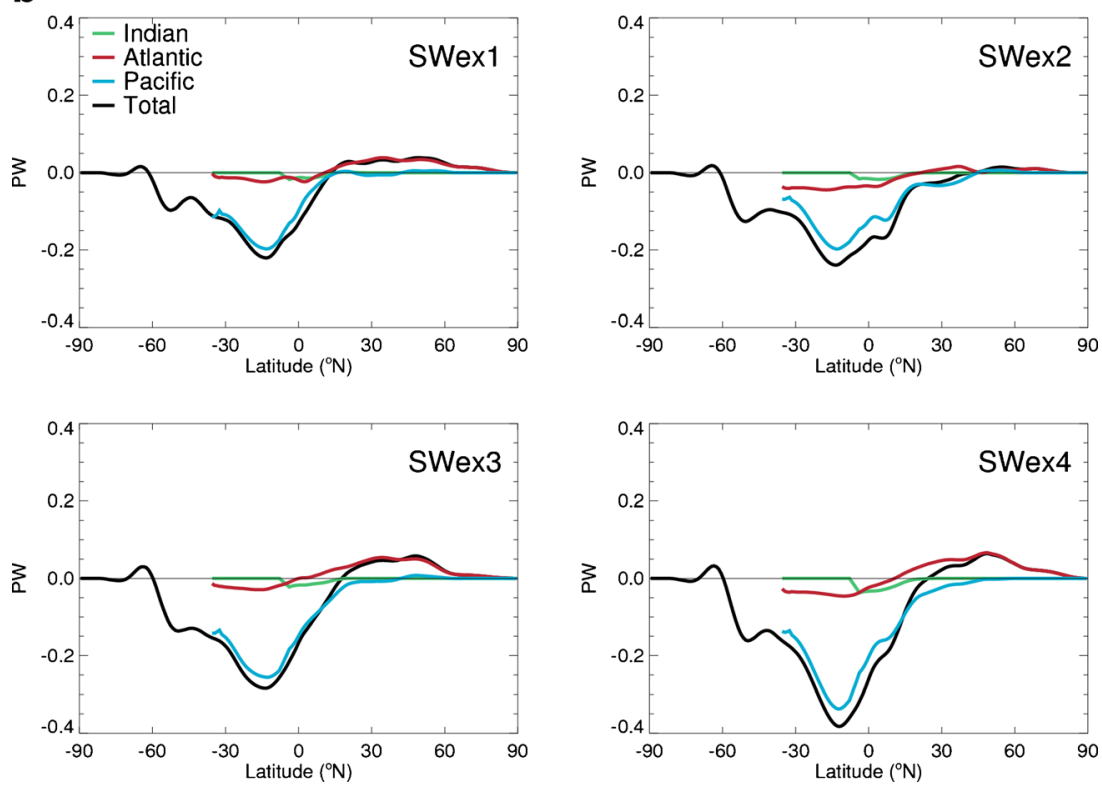
in contrast to the Haywood et al. [25] experiments (Fig. 8a) and then primarily within the Pacific Ocean (Fig. 11b).

Despite the differing motivations for the experiments, different experimental set-ups and the use of two independently developed models, both studies arrived at a similar conclusion. Imposing hemispheric albedo symmetry to more closely match observations impacts the large-scale circulation, large-scale heat transport, but not tropical precipitation. In both the Kay et al. [36] and Hawcroft et al. [24] studies, the experiments produce tropical precipitation that is largely unaffected by imposing hemispheric energy symmetry because the resulting crossequatorial heat transport changes occurred in the ocean not the atmosphere. These two studies can be contrasted with the improvements in tropical precipitation seen in Haywood et al. [25]. The relationship between cross-equatorial atmospheric heat transport and tropical precipitation asymmetry noted in previous studies [e.g., 13, 73] is reproduced in Haywood et al., though the changes in cross-equatorial atmospheric energy transport can be associated with the local discontinuity in TOA net flux which is induced by the experimental design, rather than a significant improvement in the model's overall performance. Together, these three studies imply that zonal mean tropical precipitation biases in models may be associated with errors in cross-equatorial atmospheric energy transport, that are not resolved by correcting remote energy budget biases, such as those in the Southern Ocean.

\section{Discussion and Conclusions}

This paper describes an assembly of a large amount of data used to construct the Earth's hemispheric energy balance. The data include multiple sources of in situ oceanic temperatures to deduce the oceanic heat content, oceanic analyses that provide ocean transports, and surface and TOA radiative flux data from CERES. Because energy and water are synonymous within the Earth system, the characteristics of the hemispheric precipitation are also reviewed. The main result of the study is summarized in Fig. 4 showing a multi-year annual average of the hemispheric energy balance and the fluxes of heat across the equator. The results of Loeb et al. [47] are also included and no attempt was made to adjust the fluxes and provide overall balance choosing to underscore the degree to which the different data sources are imbalanced. A notable feature of the energy balance portrayed is the near hemispheric symmetry in the TOA energy balance as has been noted in other studies in contrast to the surface radiative fluxes that are slightly more asymmetrical. At the TOA, the SH is slightly out of balance and a small amount of heat $\left(0.9 \mathrm{Wm}^{-2}\right)$ is absorbed by the Southern oceans (Fig. 1) whereas the NH appears to be almost in balance. The slight energy imbalance between the hemispheres implies a net transport of heat across the equator from the warmed SH to the NH (Fig. 2) which is realized as a
$0.45 \mathrm{PW}$ transport by the oceans and a smaller southward transport of heat $(0.22-0.33 \mathrm{PW})$ by the atmosphere. The turbulent fluxes, deduced in this study from the residual of the net balance at the surface and the surface radiative fluxes, are larger in the $\mathrm{SH}$ by about $3 \mathrm{Wm}^{-2}$. The hemispheric precipitation is also balanced to approximately $3 \mathrm{Wm}^{-2}$ according to GPCP data with slightly more precipitation accumulating $(4 \%)$ in the NH. Precipitation in each hemisphere has very different properties according to CloudSat data that indicates a higher frequency of precipitation in the SH implying more intense precipitation in the $\mathrm{NH}$.

The relationship between the hemispheric energy balance and precipitation in climate models has previously been tendered as an important control on model precipitation biases. The recent studies discussed here [24, 36], which employed two independently developed fully coupled climate models, indicate that simple improvements to the zonal mean energy balance, which lead to changes in total (ocean plus atmosphere) meridional energy transport, do not yield improvements to tropical precipitation biases, as implied by previous studies using aquaplanet or slab ocean configurations. It appears that the precipitation biases are associated with model problems in representing the cross-equatorial heat transport by the atmosphere (e.g., Figure 9) whereas the adjustments to hemispheric equilibration of the TOA budget appear to occur mostly in the oceans. Reducing the underlying physical biases in climate models which cause these biases appears to be a necessary and a challenging hurdle to improve both the energy and precipitation budgets in global models.

Acknowledgments Many different sources of data were used in this study. We gratefully acknowledge the help of Seiji Kato for access to the latest version of CERES EBAF data. We thank Doris Folini, Urs Beyerle, and Thierry Corti for their efforts in post-processing and downloading the CMIP5 data. Furthermore, we thank Veronica Nieves, Dimitris Menemenlis, Carmen Boening, and Tong Lee for providing the ocean datasets and useful discussions. Andy Jones is thanked for providing additional analyses. This work was supported under NASA Grants NNN13D984T and NNN12AA01C. MH and JMH were supported by the Natural Environment Research Council/Department for International Development via the Future Climates for Africa (FCFA) funded project Improving Model Processes for African Climate (IMPALA, NE/ M017265/1). JMH was supported by the Joint UK DECC/Defra Met Office Hadley Centre Climate Program (GA01101). JEK was supported by start-up funds awarded to her by the University of Colorado and the Cooperative Institute for Research in Environmental Sciences (CIRES).

\section{References}

1. Adler RF, Huffman GJ, Chang A, Ferraro R, Xie PP, Janowiak J, Rudolf B, Schneider U, Curtis S, Bolvin D, Gruber A, Susskind J, Arkin P, Nelkin E. The version-2 global precipitation climatology project (GPCP) monthly precipitation analysis (1979-present). J Hydrometeorol. 2003;4(6):1147-67.

2. Allen MR, Ingram WJ. Constraints on future changes in climate and the hydrologic cycle. Nature. 2002;419(6903):224-32. 
3. Andrews T, Forster PM, Gregory JM. A surface energy perspective on climate change. J Clim. 2009;22(10):2557-70.

4. Antonov JI, Levitus S, Boyer TP. Climatological annual cycle of ocean heat content. Geophys Res Lett. 2004;31(4).

5. Balmaseda MA, Hernandez F, Storto A, Palmer MD, Alves O, Shi $\mathrm{L}$, et al. The ocean reanalyses intercomparison project (ORA-IP). J Oper Oceanogr. 2015;8(sup1):s80-97.

6. Behrangi A, Stephens G, Adler RF, Huffman GJ, Lambrigtsen B, Lebsock M. An update on the oceanic precipitation rate and its zonal distribution in light of advanced observations from space. J Clim. 2014;27(11):3957-65.

7. Behringer, D. W.. The global ocean data assimilation system (GODAS) at NCEP, paper presented at 11th Symposium on Integrated Observing and Assimilation Systems for the Atmosphere, Oceans, and Land Surface (IOAS-AOLS). Am. Meteorol. Soc., San Antonio, Tex. 2007.

8. Berry DI, Kent EC. Air-sea fluxes from ICOADS: the construction of a new gridded dataset with uncertainty estimates. Int J Climatol. 2011;31(7):987-1001. doi:10.1002/joc.2059.

9. Bindoff NL, Willebrand J, Artale V, Cazenave A, Gregory J, Gulev S, Hanawa K, Le Quéré C, Levitus S, Nojiri Y, Shum CK, Talley LD, Unnikrishnan A. Observations: oceanic climate change and sea level. In: Solomon S, Qin D, Manning M, Chen Z, Marquis M, Averyt KB, Tignor M, Miller HL, editors. In: climate change 2007: the physical science basis. Contribution of Working Group I to the Fourth Assessment Report of the Intergovernmental Panel on Climate Change. Cambridge: Cambridge University Press; 2007.

10. Bodas-Salcedo A, Williams KD, Ringer MA, Beau I, Cole JN, Dufresne JL, Koshiro T, Stevens B, Wang Z, Yokohata T. Origins of the solar radiation biases over the Southern Ocean in CFMIP2 models. J Clim. 2014;27(1):41-56.

11. Bosilovich MG, Robertson FR, Chen J. Global energy and water budgets in MERRA. J Clim. 2011;24(22):5721-39.

12. Bosilovich MG, Chen J, Robertson FR, Adler RF. Evaluation of global precipitation in reanalyses. J Appl Meteorol Climatol. 2008;47(9):2279-99.

13. Cvijanovic I, Chiang JC. Global energy budget changes to high latitude North Atlantic cooling and the tropical ITCZ response. Clim Dyn. 2013;40(5-6):1435-52.

14. Dee DP, Uppala SM, Simmons AJ, Berrisford P, Poli P, Kobayashi $\mathrm{S}$, Andrae U, et al. The ERA-interim reanalysis: configuration and performance of the data assimilation system. Q J R Meteorol Soc. 2011;137(656):553-97.

15. Doelling DR, Loeb NG, Keyes DF, Nordeen ML, Morstad D, Nguyen C, et al. Geostationary enhanced temporal interpolation for CERES flux products. J Atmos Ocean Technol. 2013;30(6): 1072-90

16. Donohoe A, Battisti DS. What determines meridional heat transport in climate models? J Clim. 2012;25(11):3832-50.

17. Donohoe A, Marshall J, Ferreira D, Mcgee D. The relationship between ITCZ location and cross-equatorial atmospheric heat transport: from the seasonal cycle to the last glacial maximum. J Clim. 2013;26(11):3597-618.

18. Forget, G. A. E. L., Campin, J. M., Heimbach, P., Hill, C. N., Ponte, R. M., \& Wunsch, C.. ECCO version 4: an integrated framework for non-linear inverse modeling and global ocean state estimation. 2015.

19. Frierson DM, Hwang YT. Extratropical influence on ITCZ shifts in slab ocean simulations of global warming. J Clim. 2012;25(2):72033.

20. Frierson DM, Hwang YT, Fučkar NS, Seager R, Kang SM, Donohoe A, et al. Contribution of ocean overturning circulation to tropical rainfall peak in the northern hemisphere. Nat Geosci. 2013;6(11):940-4.
21. Ganachaud A, Wunsch C. Large-Scale Ocean heat and freshwater transports during the World Ocean circulation experiment. J Clim. 2003;16(4):696-705.

22. Hakuba MZ, Folini D, Schaepman-Strub G, Wild M. Solar absorption over Europe from collocated surface and satellite observations. J Geophys Res Atmos. 2014;119(6):3420-37.

23. Hakuba, MZ, Folini, D., \& Wild, M. On the zonal near constancy of fractional solar absorption in the atmosphere. J Clim. 2016. doi:10.1175/JCLI-D-15-0277.1.

24. Hawcroft M, Haywood J, Collins M, Jones A, Jones AC, Stephens G. Southern albedo, interhemispheric energy transports and the ITCZ: global impacts of biases in a coupled model. Clim Dyn. 2016. doi:10.1007/s00382-016-3205-5.

25. Haywood JM, Jones A, Dunstone N, Milton S, Vellinga M, BodasSalcedo A, et al. The impact of equilibrating hemispheric albedos on tropical performance in the HadGEM2-ES coupled climate model. Geophys Res Lett. 2016;43(1):395-403.

26. Huffman GJ, Adler RF, Bolvin DT, Gu G. Improving the global precipitation record: GPCP version 2.1. Geophys Res Lett. 2009;36(17):L17808.

27. Hurrell, J., Holland, M. M., Gent, P. R , Ghan, S., Kay, J. E., Kushner, P., Lamarque, J-F., Large, W. G., Lawrence, D., Lindsay, K., Lipscomb, W. H., Long, M., Mahowald, N., Marsh, D., Neale, R., Rasch, P., Vavrus, S., Vertenstein, M., Bader, D., Collins, W. D., Hack, J. J., Kiehl, J. and S. Marshall. The Community Earth System Model: A Framework for Collaborative Research. Bull Am Meteor. 2013.

28. Hwang YT, Frierson DM. Link between the double-intertropical convergence zone problem and cloud biases over the Southern Ocean. Proc Natl Acad Sci. 2013;110(13):4935-40.

29. Kanamitsu M, Ebisuzaki W, Woollen J, Yang S-K, Hnilo JJ, Fiorino M, Potter GL. NCEP-DOE AMIP-II reanalysis (R-2). Bull Am Meteorol Soc. 2002;83(11):1631-43.

30. Kang SM, Held IM, Frierson DMW, Zhao M. The response of the ITCZ to extratropical thermal forcing: idealized slab-ocean experiments with a GCM. J Clim. 2008;21:3521-32.

31. Kang SM, Frierson DM, Held IM. The tropical response to extratropical thermal forcing in an idealized GCM: the importance of radiative feedbacks and convective parameterization. J Atmos Sci. 2009;66(9):2812-27.

32. Kang SM, Seager R, Frierson DMW, X. L. Croll revisited: why is the northern hemisphere warmer than the southern hemisphere? Clim Dyn. 2014;44(5):1457-72.

33. Kato, S., Rose, F. G., Sun-Mack, S., Miller, W. F., Chen, Y., Rutan, D. A., ... \& Winker, D. M. Improvements of top-of-atmosphere and surface irradiance computations with CALIPSO-, CloudSat-, and MODIS-derived cloud and aerosol properties. J Geophys Res: Atmos. 2011;116(D19).

34. Kato S, Loeb NG, Rose FG, Doelling DR, Rutan DA, Caldwell TE, et al. Surface irradiances consistent with CERES-derived top-ofatmosphere shortwave and longwave irradiances. J Clim. 2013;26(9):2719-40.

35. Kay JE, Deser C, Phillips A, Mai A, Hannay C, Strand G, et al. The Community Earth System Model (CESM) large ensemble project: a community resource for studying climate change in the presence of internal climate variability. Bull Am Meteorol Soc. 2015;96(8): 1333-49.

36. Kay JE, Wall C, Yettella V, Medeiros B, Hannay C, Caldwell P, Bitz C. Global climate impacts of fixing the Southern Ocean shortwave radiation bias in the Community Earth System Model. J Clim. 2016a. doi:10.1175/JCLI-D-15-0358.1.

37. Kay JE, Bourdages L, Chepfer H, Miller N, Morrison A, Yettella V, Eaton B. Evaluating and improving cloud phase in the Community Atmosphere Model version 5 using spaceborne lidar observations. J Geophys Res - Atmos. 2016b. doi:10.1002/2015JD024699. 
38. Köhl A. Evaluation of the GECCO2 ocean synthesis: transports of volume, heat and freshwater in the Atlantic. Q J R Meteorol Soc. 2015;141(686):166-81.

39. Kubota M, Iwasaka N, Kizu S, Konda M, Kutsuwada K. Japanese ocean flux data sets with use of remote sensing observations (JOFURO). J Oceanogr. 2002;58(1):213-25.

40. Large WG, Yeager SG. The global climatology of an interannually varying air-sea flux data set. Clim Dyn. 2009;33(2-3):341-64.

41. L'Ecuyer TS, Beaudoing HK, Rodell M, Olson W, Lin B, Kato S, et al. The observed state of the energy budget in the early twentyfirst century. J Clim. 2015;28(21):8319-46.

42. Levitus, S., Antonov, J. I., Boyer, T. P., Baranova, O. K., Garcia, H. E., Locarnini, R. A., ... \& Zweng, M. M. (2012). World ocean heat content and thermosteric sea level change (0-2000 m), 1955-2010. Geophys Res Lett. 39(10).

43. Llovel W, Willis JK, Landerer FW, Fukumori I. Deep-ocean contribution to sea level and energy budget not detectable over the past decade. Nat Clim Chang. 2014;4(11):1031-5.

44. Liu C, Allan RP, Berrisford P, Mayer M, Hyder P, Loeb N, et al. Combining satellite observations and reanalysis energy transports to estimate global net surface energy fluxes 1985-2012. J Geophys Res Atmos. 2015;120(18):9374-89.

45. Loeb NG, Wielicki BA, Doelling DR, Smith GL, Keyes DF, Kato $\mathrm{S}$, et al. Toward optimal closure of the Earth's top-of-atmosphere radiation budget. J Clim. 2009;22(3):748-66.

46. Loeb NG, Lyman JM, Johnson GC, Allan RP, Doelling DR, Wong $\mathrm{T}$, et al. . Observed changes in top-of-the-atmosphere radiation and upper-ocean heating consistent within uncertainty. Nat Geosci. 2012;5(2):110-3.

47. Loeb, N. G., Wang, H., Cheng, A., Kato, S., Fasullo, J. T., Xu, K. M., \& Allan, R. P.. Observational constraints on atmospheric and oceanic cross-equatorial heat transports: revisiting the precipitation asymmetry problem in climate models. Clim Dyn. 2015;1-19.

48. Mace, G. G., Zhang, Q., Vaughan, M., Marchand, R., Stephens, G., Trepte, C., \& Winker, D. (2009). A description of hydrometeor layer occurrence statistics derived from the first year of merged Cloudsat and CALIPSO data. J Geophys Res: Atmos, 114(D8).

49. Marshall J, Donohoe A, Ferreira D, McGee D. The ocean's role in setting the mean position of the inter-tropical convergence zone. Clim Dyn. 2014;42(7-8):1967-79.

50. Nieves V, Willis JK, Patzert WC. Recent hiatus caused by decadal shift in indo-Pacific heating. Science. 2015;349(6247):532-5.

51. O'Gorman PA, Allan RP, Byrne MP, Previdi M. Energetic constraints on precipitation under climate change. Surv Geophys. 2012;33(3-4):585-608.

52. Peixoto JP, Oort AH. Physics of climate. New York, NY: American Institute of Physics; 1992.

53. Rienecker MM, Suarez MJ, Gelaro R, Todling R, Bacmeister J, Liu E, Bosilovich MG, Schubert SD, et al. MERRA: NASA's modernera retrospective analysis for research and applications. J Clim. 2011;24(14):3624-48.

54. Roemmich, D., Church, J., Gilson, J., Monselesan, D., Sutton, P., \& Wijffels, S. (2015). Unabated planetary warming and its ocean structure since 2006. Nat Clim Chang

55. Roemmich D, Gilson J. The 2004-2008 mean and annual cycle of temperature, salinity, and steric height in the global ocean from the Argo program. Prog Oceanogr. 2009;82(2):81-100.

56. Rutan, D., Rose, F., Roman, M., Manalo-Smith, N., Schaaf, C., \& Charlock, T.. Development and assessment of broadband surface albedo from Clouds and the Earth's Radiant Energy System Clouds and Radiation Swath data product. J Geophys Res: Atmos. 2009;114(D8)

57. Simmons AJ, Poli P, Dee DP, Berrisford P, Hersbach H, Kobayashi S, Peubey C. Estimating low-frequency variability and trends in atmospheric temperature using ERA-interim. Q J R Meteorol Soc. 2014;140(679):329-53.
58. Smalley M, L'Ecuyer T, Lebsock M, Haynes J. A comparison of precipitation occurrence from the NCEP stage IV QPE product and the CloudSat cloud profiling radar. J Hydrometeorol. 2014;15(1):444-58.

59. Stephens, G. L., Vane, D. G., Tanelli, S., Im, E., Durden, S., Rokey, M., ... \& L'Ecuyer, T.. CloudSat mission: Performance and early science after the first year of operation. J Geophys Res: Atmos. 2008;113(D8).

60. Stephens GL, Hu Y. Are climate-related changes to the character of global-mean precipitation predictable? Environ Res Lett. 2010;5(2):025209.

61. Stephens GL, L'Ecuyer T, Forbes R, Gettlemen A, Golaz J-C, Bodas-Salcedo A, Suzuki K, Gabriel P, Haynes J. Dreary state of precipitation in global models. J Geophys Res. 2010;115:D24211. doi:10.1029/2010JD014532.

62. Stephens GL, Li J, Wild M, Clayson CA, Loeb N, Kato S, et al. An update on Earth's energy balance in light of the latest global observations. Nat Geosci. 2012a;5(10):691-6.

63. Stephens GL, Wild M, Stackhouse Jr PW, L'Ecuyer T, Kato S, Henderson DS. The global character of the flux of downward longwave radiation. J Clim. 2012b;25(7):2329-40.

64. Stephens GL, L'Ecuyer T. The Earth's energy balance. Atmos Res. 2015;166:195-203. doi:10.1016/j.atmosres.2015.06.024.

65. Stephens GL, O’Brien D, Webster PJ, Pilewski P, Kato S, Li J. The albedo of Earth. Rev Geophys. 2015;53:141-63. doi:10.1002/2014 RG000449.

66. Stone PH. Constraints on dynamical transports of energy on a spherical planet. Dyn Atmos Oceans. 1978;2(2):123-39. doi:10.1016/0377-0265(78)90006-4.

67. Storto A, Masina S, Dobricic S. Estimation and impact of nonuniform horizontal correlation length scales for global ocean physical analyses. J Atmos Ocean Technol. 2014;31(10):2330-49.

68. Taylor KE, Stouffer RJ, Meehl GA. A summary of the CMIP5 experiment design. Bull Am Meteorol Soc. 2012;93:485-98.

69. Trenberth KE, Fasullo JT. Simulation of present-day and twentyfirst- century energy budgets of the southern oceans. J Clim. 2010;23:440-54. doi:10.1175/2009JCLI3152.1.

70. Trenberth KE, Fasullo JT, Balmaseda MA. Earth's energy imbalance. J Clim. 2014;27:3129-44. doi:10.1175/JCLI-D-13-00294.

71. Valdivieso, M., Haines, K., Balmaseda, M., Chang, Y. S., Drevillon, M., Ferry, N., ... \& Wang, X.. An assessment of air-sea heat fluxes from ocean and coupled reanalyses. Clim Dyn. 2015;1-26.

72. Voigt A, Stevens B, Bader J, Mauritsen T. The observed hemispheric symmetry in reflected shortwave irradiance. J Clim. 2013;26(2):46877.

73. Voigt A, Stevens B, Bader J, Mauritsen T. Compensation of hemispheric albedo asymmetries by shifts of the ITCZ and tropical clouds. J Clim. 2014;27(3):1029-45.

74. Von der Haar TH, Oort AH. New estimate of annual poleward energy transport by northern hemisphere oceans. J Phys Oceanogr. 1973;3:169-72.

75. von Schuckmann KV, Le Traon PYL. How well can we derive Global Ocean indicators from Argo data? Ocean Sci. 2011;7(6):783-91.

76. Wild M, Liepert $\mathrm{B}$. The earth radiation balance as driver of the global hydrological cycle. Environ Res Lett. 2010;5(2):025203.

77. Wong T, Wielicki BA, Lee III RB, Smith GL, Bush KA, Willis JK. Reexamination of the observed decadal variability of the earth radiation budget using altitude-corrected ERBE/ERBS nonscanner WFOV data. J Clim. 2006;19(16):4028-40.

78. Yoshimori M, Broccoli AJ. Equilibrium response of an atmospheremixed layer ocean model to different radiative forcing agents, global and zonal mean response. J Clim. 2008;21:4399-423.

79. Yu, L., Jin, X., \& Weller, R. A. (2008). Multidecade Global Flux Datasets from the Objectively Analyzed Air-sea Fluxes (OAFlux) Project: Latent and sensible heat fluxes, ocean evaporation, and related surface meteorological variables. OAFlux Project Technical Report OA-2008-01, 64 pp. 